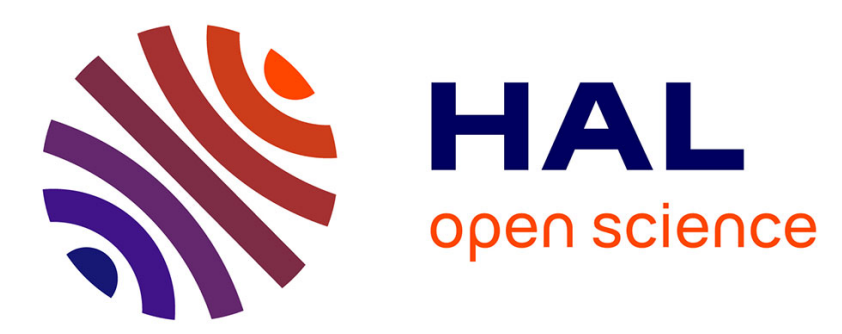

\title{
Space charge behavior in XLPE cable insulation under ac stress and its relation to thermo-electrical aging
}

Dongxin He, Xiaoran Wang, Hongshun Liu, Qingquan Li, G. Teyssedre

\section{To cite this version:}

Dongxin He, Xiaoran Wang, Hongshun Liu, Qingquan Li, G. Teyssedre. Space charge behavior in XLPE cable insulation under ac stress and its relation to thermo-electrical aging. IEEE Transactions on Dielectrics and Electrical Insulation, 2018, 25 (2), pp.541-550. 10.1109/TDEI.2017.006958 . hal02396064

\section{HAL Id: hal-02396064 https://hal.science/hal-02396064}

Submitted on 24 Nov 2020

HAL is a multi-disciplinary open access archive for the deposit and dissemination of scientific research documents, whether they are published or not. The documents may come from teaching and research institutions in France or abroad, or from public or private research centers.
L'archive ouverte pluridisciplinaire HAL, est destinée au dépôt et à la diffusion de documents scientifiques de niveau recherche, publiés ou non, émanant des établissements d'enseignement et de recherche français ou étrangers, des laboratoires publics ou privés. 


\title{
Space Charge Behavior in XLPE Cable Insulation Under ac Stress and Its Relation to Thermo-electrical Aging
}

\author{
Dongxin He, Xiaoran Wang, Hongshun Liu, Qingquan Li \\ Shandong Provincial Key laboratory of UHV Transmission Technology and Equipment \\ School of Electrical Engineering, Shandong University \\ Jinan 250061, China \\ and Gilbert Teyssèdre \\ University of Toulouse; UPS, INPT, CNRS; LAPLACE (Laboratoire Plasma et Conversion d'Energie); 118 Route de Narbonne, \\ F-31062 Toulouse Cedex 9, France
}

\begin{abstract}
The space charge features of cable insulation peelings are investigated under ac stress as a function of electrical aging imposed previously on cable sections. The investigated samples are $230-\mu \mathrm{m}$-thick peelings of crosslinked polyethylene cable insulation. The space charge profiles are resolved into 32 symmetric phase angles under $50 \mathrm{~Hz}$ ac stress. The space charge density in the phase angle of maximum applied field is the largest, as expected, but does not change visibly as a function of aging time. A method that involves averaging space charge in all phases is proposed. The all-phase averaged space charge, which appears in essence as stationary charge, exhibits an obvious increasing trend with stressing time. The aging characteristics of space charge formed under ac stress are investigated considering the all-phase averaged profiles, and the mechanical properties and degree of crosslinking are characterized as complementary methods. The change in the accumulation of space charge under ac stress follows opposite trends unlike the degree of crosslinking, which means that space charge under ac stress has a close relationship with defect concentration in cable insulation. This research contributes to the understanding of space charge features under ac conditions and the understanding of the ac aging principle of cable insulation.
\end{abstract}

Index Terms-Space charge, XLPE insulation, ac, aging, cable

\section{INTRODUCTION}

Crosslinked polyethylene (XLPE) insulated cables are widely employed in power transmission and distribution systems because of their remarkable properties, such as high dielectric strength, low dielectric loss, good thermal and aging stress endurance, and convenient construction. The reliability of power cables is essential to the safety of power systems. However, the dielectric strength of cables declines under the effect of ac electrical and thermal stresses when in operation. The gradual degradation processes caused by composite stress on dielectrics, known as electrical aging, have a close relationship with the reliability of electrical equipment and are of special concern for electrical companies but are not completely recognized.

When dielectrics are subjected to electrical stress, space charges, which are electrical charges stored in a localized position, are generated in insulation bulk or at the surface and prominently influence the insulation properties [1, 2]. Numerous research results postulate that space charge plays a significant part in the aging of cable insulation and might control the lifetime [3, 4]. The energy released by space charge-mediated processes may indeed constitute the leading mechanism in material evolution [5]. In recent years, space charge has been shown to generate a high electric field and substantially distort the local electrical strength, with field intensification processes triggering partial discharges [6]. At the interface level, charge injection and extraction are thought to destroy the microstructure of polymeric material and initiate electrical tree, which may propagate across the insulation and lead to dielectric breakdown $[7,8]$.

Space charge characteristics under dc conditions have been studied for a long time, and their negative effect on dielectrics is caused by the continuous accumulation of charges of a given polarity producing local field strengthening $[9,10]$. Previous reports show that space charge quantity under dc stress has a positive correlation with aging time; thus, it can represent a characteristic index for the aging degree [11, 12]. Space charges under ac stress have not been investigated extensively because of the difficulty of measuring space charge with a resolution along the ac phase [13] and the relatively smaller charge amount compared with dc stress. Intuitively and according to modeling, physical processes at interfaces should substantially affect space charge under ac [14]. However, space charge theories under ac have not been corroborated by experience. Most electrical apparatuses are operated under ac stress. Hence, the space charge 
under ac conditions and its relationship with aging need to be studied in depth.

The net space charge quantity stored under ac stress is smaller than that under dc stress because of repeated injections and extraction of charges in negative and positive half-periods, and the quantity becomes low with the increase in frequency [15]. Initial studies observed scarce space charge under ac stress with a frequency of $50 \mathrm{~Hz}$, relatively low ac electrical field, and short stressing time [16]. Recent studies also reported the existence of space charge at power frequency. These studies have been conducted indirectly by using various approaches; for example, electroluminescence from dielectrics under ac stress, which is much more intense than that under dc stress, is considered to be related to space charge dynamic behavior under ac stress [5]. Reports on direct charge measurements can be distinguished between those carried in post-stressing under ac stress and those during ac stressing with or without phase resolution. The detection of residual space charge in the depolarization process does not require specific equipment unlike in the dc case, and several reports show evidence of such residual charge [17-19]. The production of charge profiles in specific phase angles under ac stressing as reported for polyethylene laminated samples requires the synchronization of acoustic or electric perturbation with the ac stress [20-25]. Most results of the aforementioned studies were obtained on a flat specimen, and accumulation within cable insulation under ac stress was reported recently [26]. Clearly, abundant experimental evidence shows that space charge behavior under ac voltage cannot be ignored.

Studies also focused on the aging characteristics of space charge under ac stress. This has been done for example with by recording the volt-off charge profiles of aged samples and analyzing the evolution of the charge density after electrical aging [27, 28]. A significant influence of ac charge transport on the breakdown process was reported [29]. In the same way, space charge decay after dc poling of samples aged under ac stress and thermal endurance was measured by Tzimas et al. [30]; the origin of space charge was interpreted in relation to impurities and additives in the cable. Mechanistic approaches of aging and failure under ac stress with the mediation of space charge processes were also discussed [31, 32, 5]. However, reports on space charge on samples aging usually adopted space charge measurement under dc voltage or the volt-off profile and did not use space charge profile under ac stress, which requires further research.

In this work, phase-resolved space charge measurements obtained on cable peelings were presented. A method that involves averaging all the charge profiles in all phase angles was presented to clearly recognize features of space charges formed under ac stress. The all-phase averaged space charge in cable peelings under different aging degrees were compared to obtain aging characteristics in relation to space charge. The mechanical properties and degree of crosslinking of cable insulation were conducted to provide an auxiliary explanation of its aging characteristics. The purpose of this study is to make contributions for the explicit comprehension of the essence of space charge under ac conditions and the relation between ac stress aging and space charge accumulation.

\section{SAMPLES AND METHODS}

\subsection{CABLE PEELINGS}

Samples were taken from an XLPE insulated HVAC cable manufactured by Qingdao Hanlan Group Co., Ltd. The insulation thickness was $4.5 \mathrm{~mm}$, and the rated voltage was $10 \mathrm{kV}$. The insulation of the cable was cut into $230-\mu \mathrm{m}$-thick and $45 \times 45 \mathrm{~mm}^{2}$ wide peelings for space charge measurement. The cutting method is schematized in Figure 1. A section of the cable was installed in a rotary machine and cut by a lathe whose knife was moving forward in a tangential direction. The width and flatness of the peelings were determined by revolving the rotation speed of the cable and the moving speed of the lathe knife. The choice of working with flat specimen was motivated by the goal to obtain the charge profile with a high spatial resolution and under a relatively high field, which would not be easily possible with medium-voltage cables. The cutting method was also employed in the European ARTEMIS Program [33, 34], and the equivalence of peelings with a full-size cable for electrical and material property investigation and space charge measurement was confirmed [35]. XLPE peelings taken from the middle layer of the cable insulation were selected for space charge measurements.

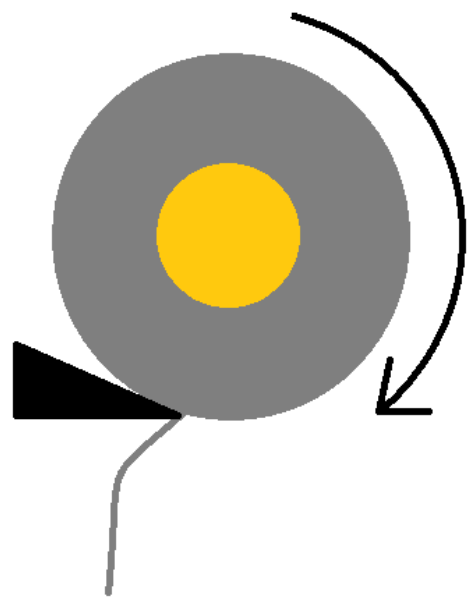

Figure 1. Cutting method scheme of cable insulation.

\subsection{SPACE CHARGE MEASUREMENT METHOD UNDER AC STRESS}

Space charge profiles were measured through the space charge measurement system for laminated samples under ac stress, whose structural diagram is shown in Figure 2. The design principle is similar to the space charge measurement system for cables introduced in a recent work [26]. The principle of the measurement system is based on pulsed electro-acoustic method, that is, the sample is submitted to pulsed electric field generated by high-voltage pulse power supply, which generates electrostatic forces on existing charges. Thus, ultrasonic waves are induced and transformed into electric signals by a piezoelectric sensor, which reflects the distribution of space charge in the sample [36].

For charge measurement under ac stress, the difficulty is the match of measurement time with ac phases compared with charge measurement under dc stress. In addition, acoustic signals need to be recorded over several periods to be averaged 
afterwards. In previous works, either trains of pulses were produced at desired positions of the phase of the ac stress [37, 38 ] or the phase of a given acoustic response was determined a posteriori using a phase recognition algorithm [24]. In this paper, the ac phase-matching circuit is designed to solve the matching problem, as shown in Figure 2.

The ac sinusoidal signal obtained from the capacitive voltage divider is transformed into a square waveform signal synchronous with high ac voltage. The square waveform signal triggers the signal generator to output 32 short square waveform signals, which control the switch of high-voltage pulse power supply. Electroacoustic signals in 32 phase angles can be measured in one sinusoidal period due to the control of phase-matching circuit on high-voltage pulse power supply. Space charge waveforms were produced by averaging more than 500 sinusoidal periods in one time, and the averaged space charge profiles in 32 phase angles were achieved with an interval of $11.25^{\circ}$.

In the space charge measurement process, $35 \mathrm{kV} / \mathrm{mm}$ (r.m.s. value) and $50 \mathrm{~Hz}$ ac electrical field were applied on the XLPE cable peeling samples for $6 \mathrm{~h}$. Space charge profiles in 32 phase angles were tested intermittently when ac voltage was applied. After stressing for $6 \mathrm{~h}$ under ac electrical field, XLPE samples were placed in short circuit, and the space charge profiles were recorded as a function of time with stress off.

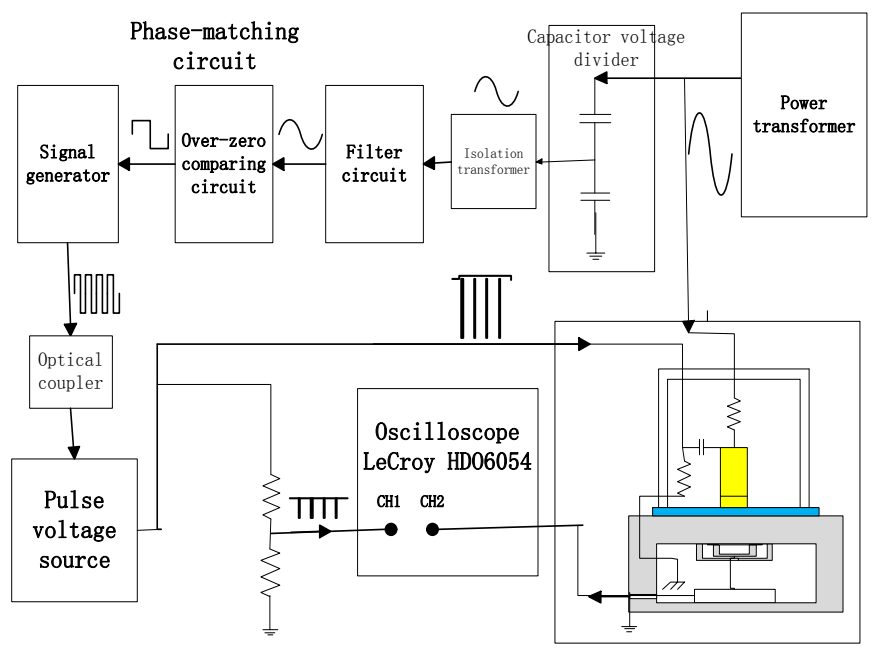

Figure 2. Space charge measurement system for laminated sample under ac conditions.

\subsection{THERMO-ELECTRIC AGING CONDITIONS}

Some cable sections aged prior to their preparation into peelings. The structure of aged cable samples is shown in Figure 3. The total length of cable section was $340 \mathrm{~mm}$, and after treating the cable terminations, the length of the remaining outer semiconducting layer in the middle part was $90 \mathrm{~mm}$. Two stress cones were installed on both sides of the cable to avoid corona or flashover under ac stress.

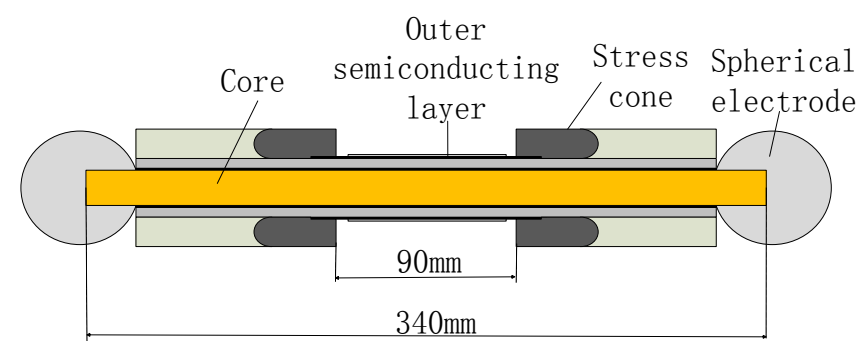

Figure 3. Structure of aged cable samples.

The cable samples for aging were placed in an oven with suited high-voltage bushing to transmit the ac high voltage to the cable sample.

Increasing the temperature caused the XLPE to soften and the mechanical performance of the XLPE to reduce considerably. XLPE material was still stiff at $103{ }^{\circ} \mathrm{C}$. At temperatures above $105{ }^{\circ} \mathrm{C}$, deformation of XLPE readily occurred, and at $114{ }^{\circ} \mathrm{C}$, the crystalline regions completely melted. The aging heat treatment temperature prescribed by IEC $60502-2-2005$ is $135^{\circ} \mathrm{C}$. Therefore, we chose three temperatures, 103,114 , and $135{ }^{\circ} \mathrm{C}$, as thermal stresses for aging. The real cable insulation in the power system was aged in the way of electrochemical aging. If the electric field applied during aging tests is too high, then the aging mechanisms may change. Hence, we chose an ac stress that is three times the rated voltage (the rated phase voltage is 8.7 $\mathrm{kV}$ for $10 \mathrm{kV}$ XLPE cable), i.e., $26.1 \mathrm{kV}$ for aging. The aged cable samples were taken out in five stages and cut into laminated peelings for space charge measurements. Table 1 shows the total aging time and sampling intervals at the three different aging conditions. The cable samples for aging were placed in three ovens set at three different aging temperatures. A picture of the integral thermo-electric aging system is shown in Figure 4.

Table 1. Total aging time and sampling interval

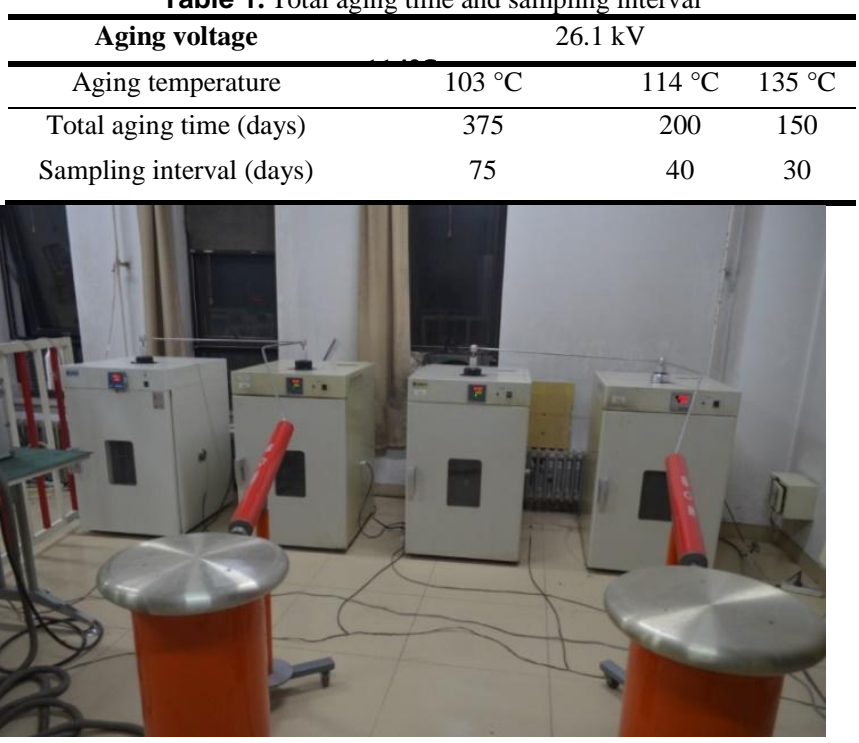

Figure 4. Picture of thermo-electric aging system.

3 RESULTS 


\subsection{SPACE CHARGE VS. PHASE ANGLE UNDER AC VOLTAGE}

One cable section was aged for 300 days under aging conditions of $103{ }^{\circ} \mathrm{C}$ temperature and $26.1 \mathrm{kV}$ ac voltage. Examples for space charge characteristics obtained on samples peeled from this cable are given in Figure 5. Space charge profiles in 32 different phase angles under ac voltage application for $6 \mathrm{~h}$ are depicted in different colors. Inner space charge within the bulk of the sample was found, whose polarity was the same as that of the upper electrode (located at the right side of the figures). The polarity of the interface charge and the inner space charge varied with the ac phase angle.

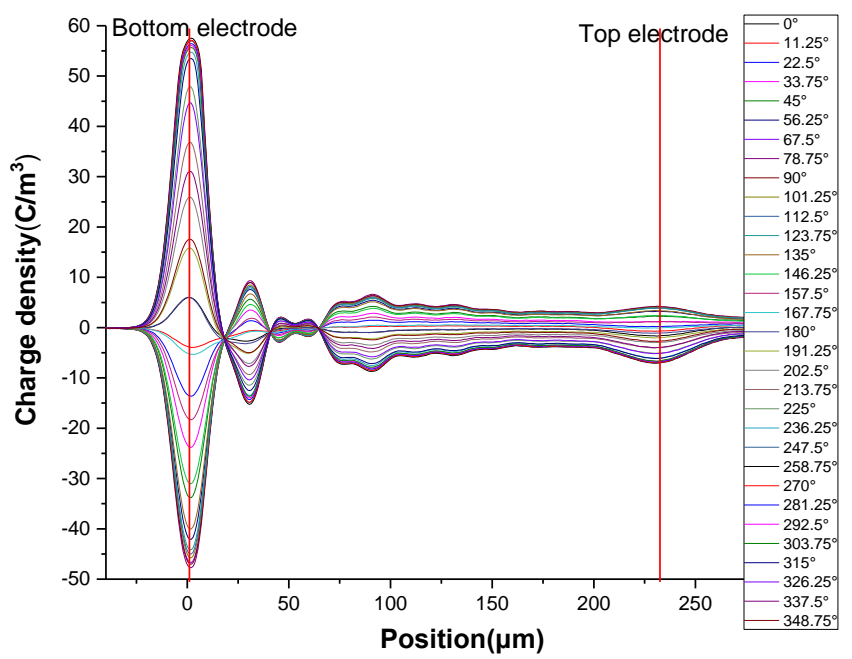

Figure 5. Space charge profiles at 32 phase angle values in cable peelings previously aged under $103^{\circ} \mathrm{C}$ and $26.1 \mathrm{kV}$ for 300 days. The angles of 90 and $270{ }^{\circ} \mathrm{C}$ respectively correspond to a maximum positive and negative voltage applied to the top electrode, as shown in the right side in the figure.

It must be stressed here that there is apparently, a substantial attenuation in space charge distribution signal, as the charge peak amplitude at the upper electrode is much lower than that at the bottom electrode. However, the space charge profile in cable peeling under dc stress did not have such attenuation, the influence charge peak at the top electrode being of the same magnitude as that at the bottom [26]. This finding means that it is not due to the attenuation of acoustic waves, all the more that test samples are relatively thin. The reasons for such apparent strong attenuation of the response under ac stress are still not known at present. Possibly the upper semiconducting electrode does not behave as a pure conducting electrode under AC stress, i.e., the influence charge may be distributed into the semiconductor electrode, thereby producing an attenuated response in the electroacoustic signal.

The amplitude and polarity of space charge in XLPE peelings change simultaneously with the phase angle under ac voltages. The charge density is largest in the phases of $90^{\circ}$ and $270^{\circ}$ (corresponding to voltage maxima) and lowest in the phases of $0^{\circ}$ and $180^{\circ}$. The amplitude of space charge is nearly proportional to real-time voltage amplitude. We considered first how space charge profiles at maximum voltage evolve with stressing time under ac. Figure 6 shows the evolution of charge profiles at $90^{\circ}$ and $270^{\circ}$ during the $6 \mathrm{~h}$ stressing time under $35 \mathrm{kV} / \mathrm{mm}$.

Meticulous inspection revealed that the space charge next to the bottom electrode in the phase of $270^{\circ}$ became slightly larger during voltage application, whereas the space charge next to the bottom electrode in the phase of $90^{\circ}$ became slightly lower. However, the variation is so faint that it is difficult to recognize in the phases of $90^{\circ}$ and 270 . A previous study [39] also indicated a slight variation of space charge in the phase angles from $0^{\circ}$ to $120^{\circ}$ under $2 \mathrm{~h}$ application of $10 \mathrm{~Hz}$ ac voltage.

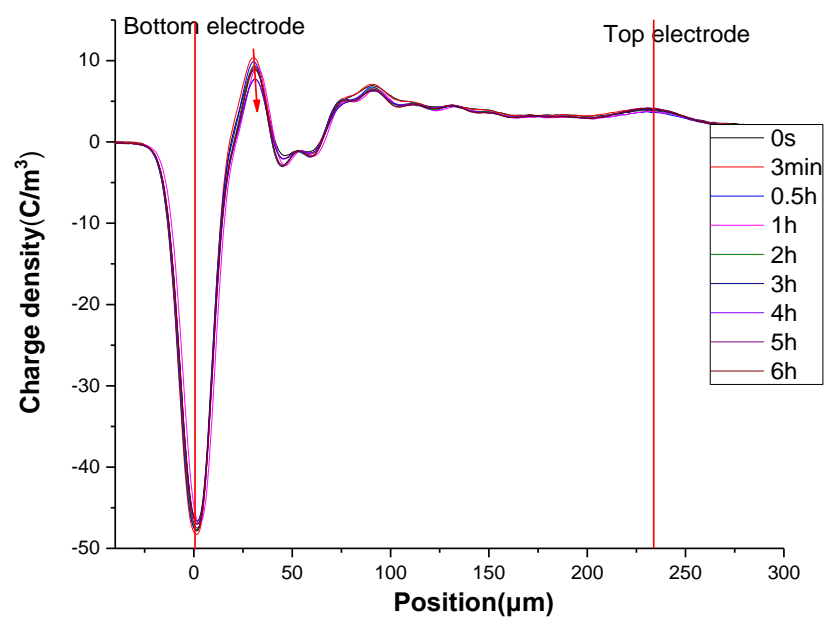

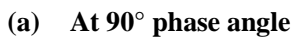

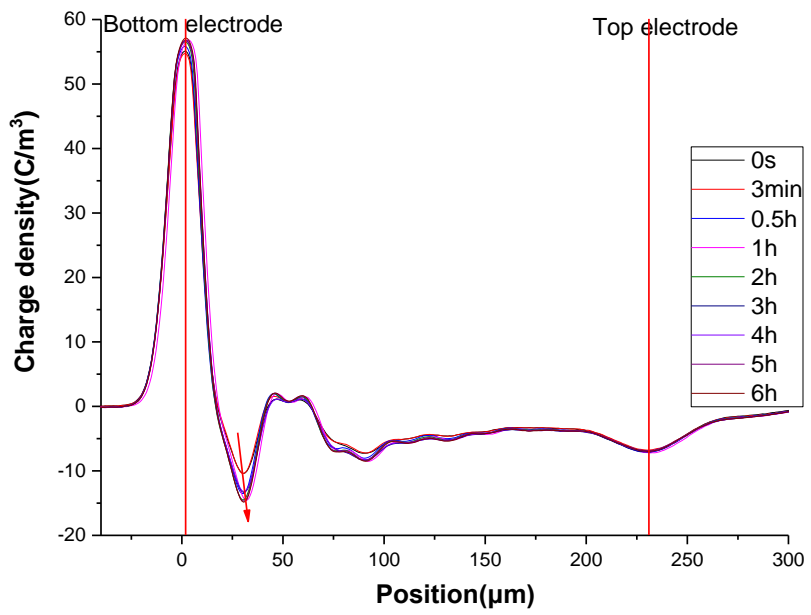

(b) At $270^{\circ}$ phase angle

Figure 6. Space charge profiles in XLPE cable peelings at phase angles of maximum voltage and its evolution with $6 \mathrm{~h}$ stressing time under a r.m.s. ac field of $35 \mathrm{kV} / \mathrm{mm}$. The cable was aged for 300 days at $103{ }^{\circ} \mathrm{C}$ under $26 \mathrm{kV}$ stress prior to peeling.

To reveal the variation of space charge formed under ac conditions, we developed a method called all-phase averaged method to identify space charge features. The method includes averaging all the space charge profiles in the 32 phase angles measured in one run; therefore, the space charge whose polarity changed between the positive and negative period was counteracted through the average.

The all-phase averaged waveforms of XLPE peelings in the $6 \mathrm{~h}$ voltage application process are shown in Figure 7. All the charge peaks of the averaged waveform increased with stressing time. Before the application of the ac stress, there 
was little space charge inside the sample bulk. Two space charge peaks close to the left-hand electrode appeared and grew gradually due to the action of the ac stress. The interface charge at the bottom electrode increased to a large extent, whereas the interface charge to the top electrode grew only slightly. The space charge amount increased quickly in the first $1 \mathrm{~h}$ of voltage application time, especially in the initial $3 \mathrm{~min}$, at which point it grew very fast. With the increase in voltage application time, the ac charge accumulation speed gradually slowed down.

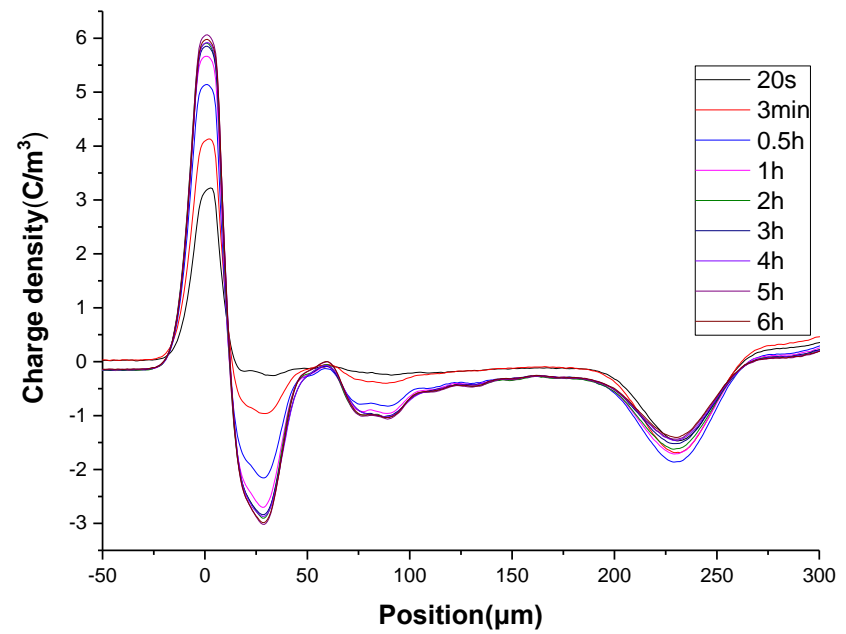

Figure 7. All-phase averaged charge profiles of XLPE peeling in $6 \mathrm{~h}$ ac stress application process. The cable was previously aged under $103{ }^{\circ} \mathrm{C}$ and $26.1 \mathrm{kV}$ for 300 days.

The experimental results show that the all-phase averaged charge waveform presents a distinct variation under the action of the ac stress and represents space charge characteristics that are more exploitable than the charge profile in the phase of $90^{\circ}$ or $270^{\circ}$. It must be realized that only a few space charge measurements under ac stress were reported in the previous studies, and often, the data were exploited at zero field crossing [27, 40]. Since in general, the residual charge is weak, it is best resolved when the capacitive charges are not present on the electrodes and overwhelm the response.

Therefore, we used all-phase averaged charge profiles to identify space charge characteristics under ac thermo-electrical aging.

\subsection{AC SPACE CHARGE VS. AGING CONDITIONS}

The all-phase averaged charge density increased with the application time of ac stress and reached maximum after $6 \mathrm{~h}$ application. Thus, we used the all-phase averaged space charge waveform at $6 \mathrm{~h}$ ac stress application to compare the space charge characteristics in different stages. The all-phase averaged space charge profiles at $6 \mathrm{~h}$ ac stress application of cable insulation peelings in different aging times at temperatures of 103,114 , and $135^{\circ} \mathrm{C}$ are shown in Figure 8.

As shown in the figure, the all-phase averaged charge density generally increased with the aging time for the cable sections. For $103{ }^{\circ} \mathrm{C}$ and $114{ }^{\circ} \mathrm{C}$ aging, the interface charge density in the bottom electrode and the upper electrode reached the maximum in the last aging stage. For the $135^{\circ} \mathrm{C}$ aging, the interface charge density in the bottom electrode in the fifth stage was slightly smaller than that in the fourth stage, whereas the interface density in the upper electrode was the largest in the fifth stage.

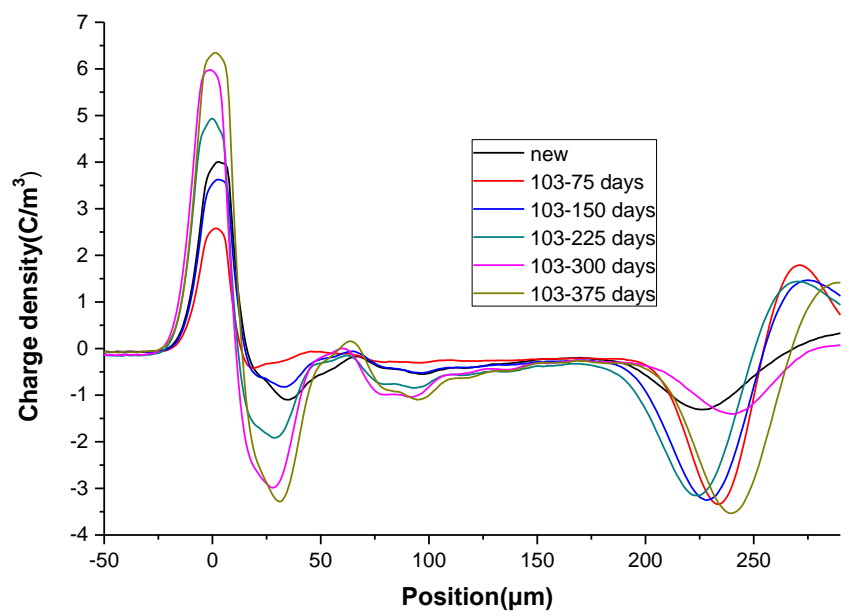

(a) $103{ }^{\circ} \mathrm{C}$

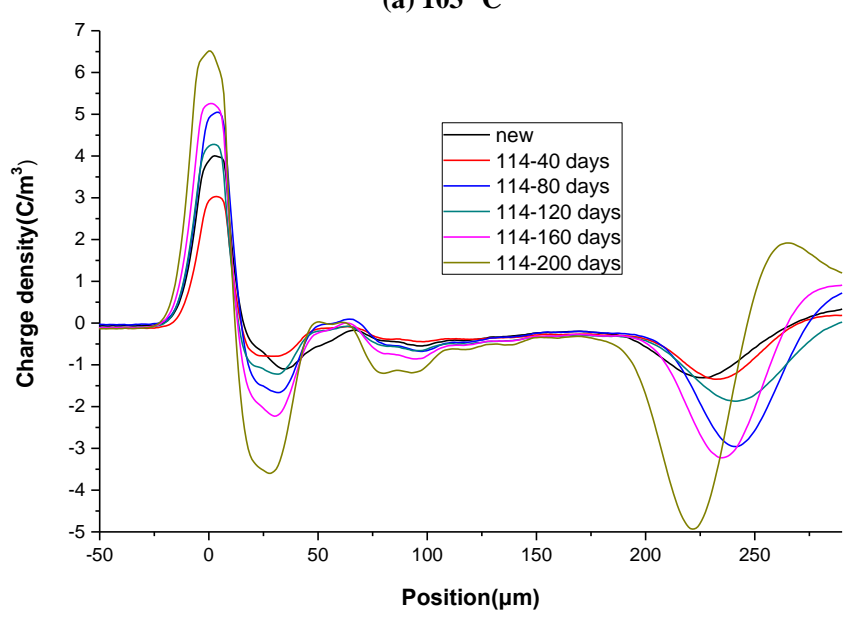

(b) $114{ }^{\circ} \mathrm{C}$

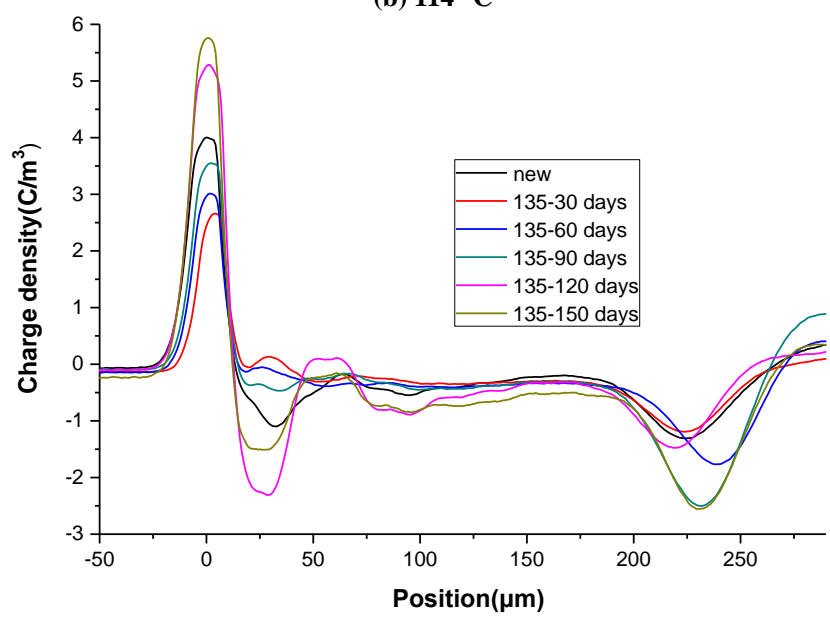

(c) $135^{\circ} \mathrm{C}$

Figure 8. All-phase average space charge waveform at $6 \mathrm{~h}$ of ac stress application of cable peelings taken from cables aged in different aging stages under temperatures of (a) $103{ }^{\circ} \mathrm{C}$, (b) $114{ }^{\circ} \mathrm{C}$, and (c) $135^{\circ} \mathrm{C}$.

The net charge quantity was obtained through the 
integration of all-phase averaged charge density, taken in absolute value, over the thickness. Figure 9 shows the charge quantity at $6 \mathrm{~h}$ ac stress application of cable peelings in different aging stages.

As shown in the figure, the trend of the charge quantity decreased at the beginning and then increased in the latter stages for the aging at all three temperatures. In the first stage, the charge quantity decreased slightly and then gradually augmented from the second stage until the fifth aging stage. The charge quantity in the last stage was $50 \%$ to $100 \%$ larger than that before aging. The kinetic of charge increase was the same at temperatures of 135 and $114{ }^{\circ} \mathrm{C}$. The increase is clearly slower at a temperature of $103{ }^{\circ} \mathrm{C}$.

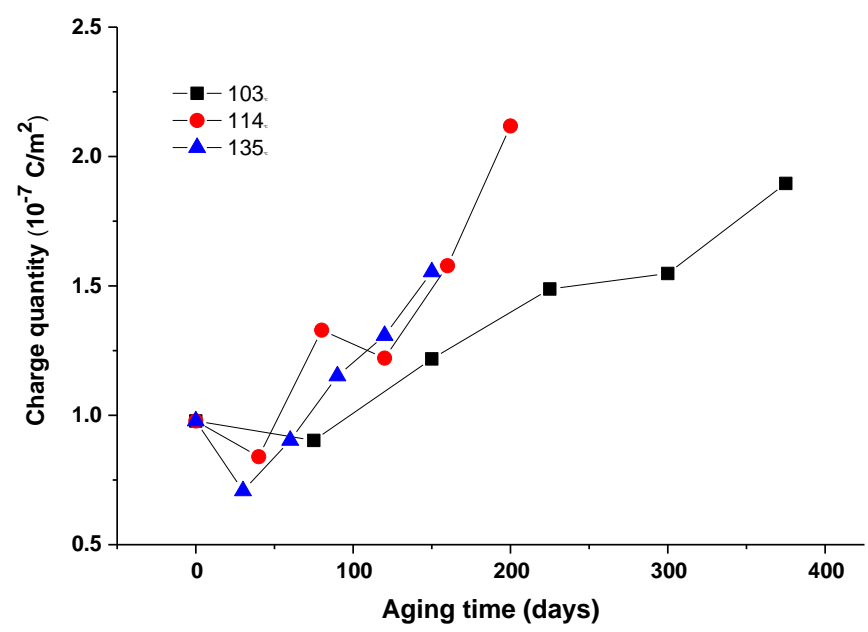

Figure 9. Charge quantity at $6 \mathrm{~h}$ ac stress application of cable peelings in different aging stages under 103,114 , and $135^{\circ} \mathrm{C}$.

\subsection{MECHANICAL AND STRUCTURAL CHANGES}

To explain space charge characteristics, we conducted relevant mechanical and chemical analyses on aged cable samples to provide auxiliary information. The tensile strength and elongation at break were tested to represent mechanical properties. The degree of crosslinking is a significant index of XLPE material integrity, which is generally characterized by the gel content [41].

A test on tensile strength and elongation at break was conducted according to IEC 60811-1-1:2001. Cable insulation was cut into dumbbell-shaped pieces and measured by a CWT6502 computer-controlled testing machine with a stretching velocity of $250 \pm 50 \mathrm{~mm} / \mathrm{min}$. The gel content was obtained through xylene immersion [42], in which the non-crosslinked portion was dissolved by xylene. Thus, the remaining fraction of polymer was considered the gel content.

The variations of tensile strength and elongation at break of cable insulation versus aging time at 103,114 , and $135{ }^{\circ} \mathrm{C}$ are shown in Figure 10. As shown in the figure, the tensile strength and the elongation at break increase at the first stage and decrease from the second stage. The elongation at break decrease from $490 \%$ before aging to $376 \%, 325 \%$, and $281 \%$ in the fifth stage under 103,114 , and $135{ }^{\circ} \mathrm{C}$. The tensile strength decreased from $20.0 \mathrm{~N} / \mathrm{m}^{2}$ before aging to $17.7,15.5$, and $14.6 \mathrm{~N} / \mathrm{m}^{2}$ in the fifth stage under 103,114 , and $135{ }^{\circ} \mathrm{C}$, which represent substantial reduction of mechanical strength.
A comparison of different aging temperatures shows that the tensile strength and the elongation at break have a faster decrease speed when aged under high temperature.

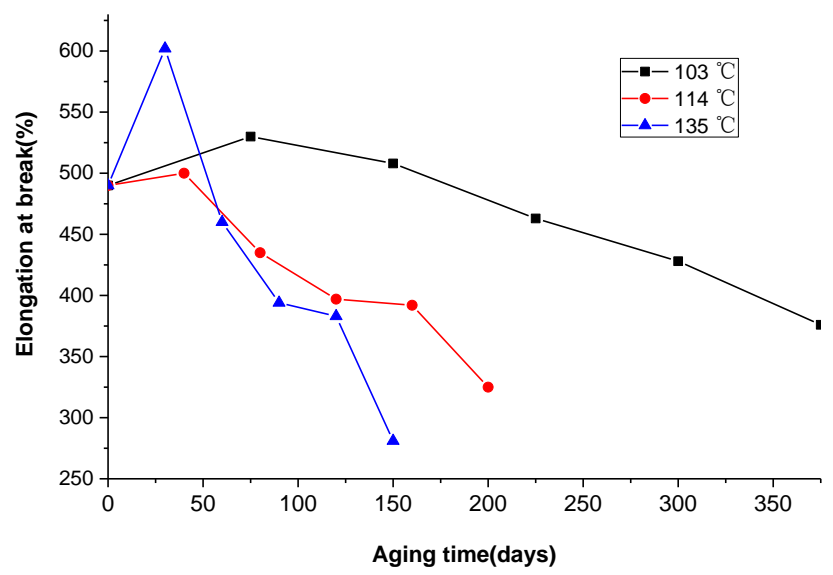

(a) Elongation at break

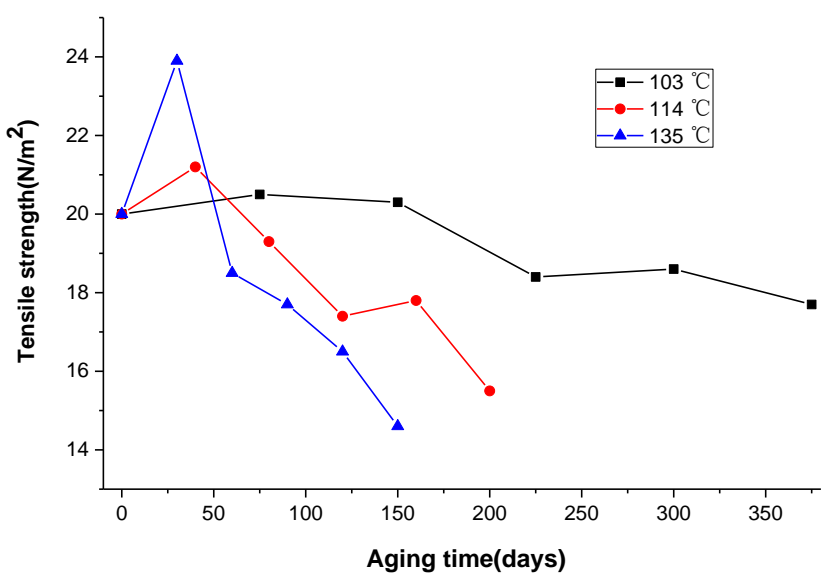

(b) Tensile strength

Figure 10. Change in mechanical properties of the insulation as function of cable aging time.

The evolution in the degree of crosslinking, i.e., the gel content, in cable insulation versus aging time under aging temperatures of 103,114 , and $135^{\circ} \mathrm{C}$ is shown in Figure 11. With the aging process under the three temperatures, the degree of crosslinking increased initially and then decreased from the second or third stages with a decreasing rate as the aging temperature increased. The degree of crosslinking in the fifth aging stage under all three temperatures was lower than that before aging.

A comparison of Figures 10 and 11 shows that the tensile strength, elongation at break, and degree of crosslinking of cable insulation follow the same variation with aging time; all increased at the beginning of aging and decreased afterwards. This finding means that mechanical properties have a strong correlation with the degree of crosslinking. When the degree of crosslinking increases or decreases, the mechanical properties correspondingly become strong or weak. 


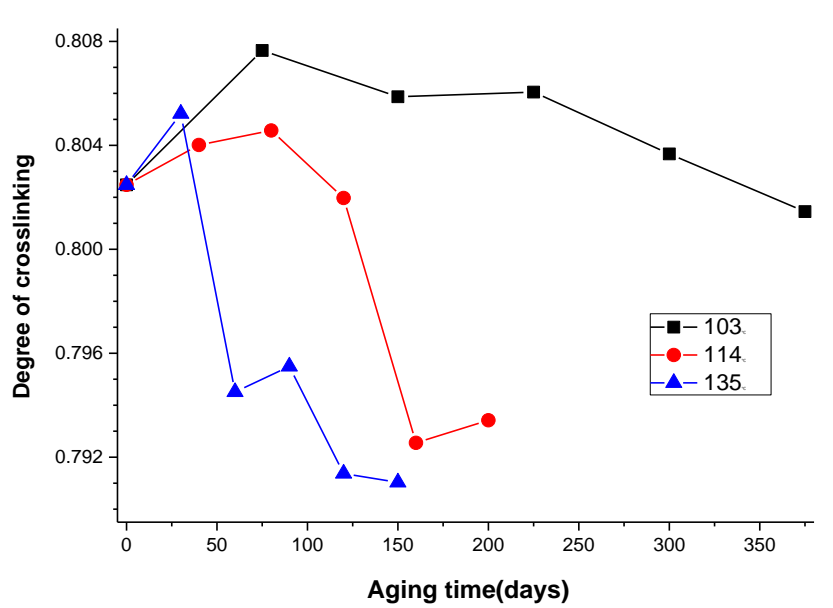

Figure 11. Change in degree of crosslinking in cable insulation versus aging time.

\section{DISCUSSION}

\subsection{ESSENCE OF SPACE CHARGE IN ALL-PHASE AVERAGED METHOD}

As described in a previous report [26], in cable insulation operated in a power system for 15 years, space charge under ac electric field can be divided into two categories: periodic charge, whose magnitude and polarity change within a phase of the ac stress, and stationary charge, which remains almost stationary in a period and slowly evolves as a function of the stressing time. The periodic charge does not obviously evolve with aging and is close to symmetrical for positive and negative half-periods of the stress. By contrast, stationary charge gradually increases as aging progresses.

On the basis of previous research results, we can evaluate the significance and the input of all-phase averaged method. The 32 phases are symmetrical in two consecutive half-periods. Hence, the influence charge (capacitive and image charges) and the periodic charge are counteracted due to the opposite polarity between negative and positive periods. The stationary charge remains and is revealed in the all-phase averaged charge profile. Clear support to the statement is given in the following.

After $6 \mathrm{~h}$ of ac stress application, the XLPE peeling sample was placed in short circuit, and the volt-off space charge was measured in the depolarization process. This followed the tests on the cable aged under $103{ }^{\circ} \mathrm{C}$ and $26.1 \mathrm{kV}$ for 300 days with phase-averaged space charge profile shown in Figure 7. The volt-off space charge profiles in the first $180 \mathrm{~s}$ of the depolarization time are shown in Figure 12. The interface charge peak on the bottom electrode and the two inner space charge peaks close to the bottom electrode decreased considerably in this time interval. Within approximately $100 \mathrm{~s}$, the inner space charge decayed nearly to zero, and the image charge to the bottom electrode was substantially reduced.

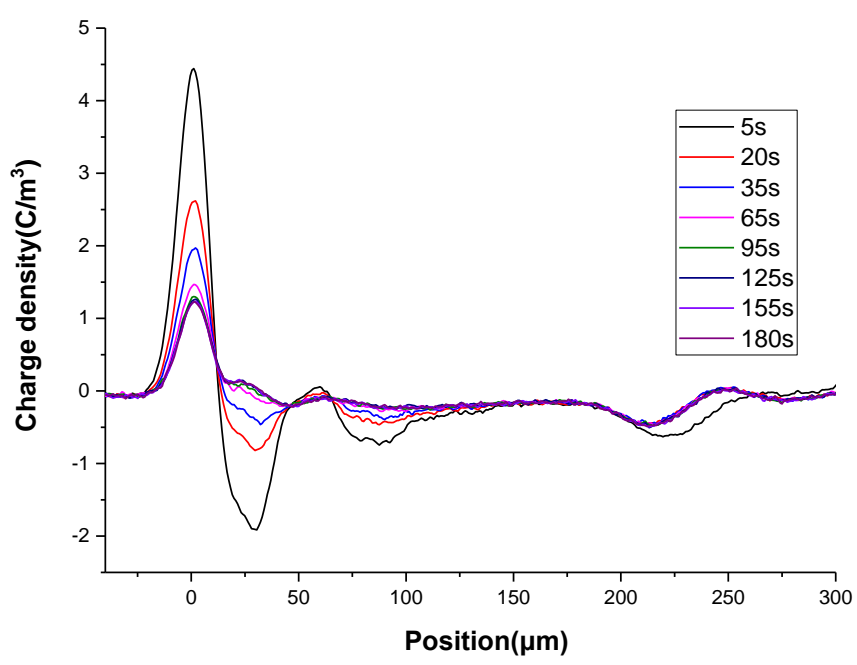

Figure 12. Volt-off space charge profiles in the depolarization process after $6 \mathrm{~h}$ ac stress application. The cable was previously aged under $103{ }^{\circ} \mathrm{C}$ and $26.1 \mathrm{kV}$ for 300 days.

A comparison of Figures 7 and 12 shows that the all-phase averaged charge waveform and the volt-off space charge profile have similar shapes; both have two inner space charge peaks close to the bottom electrode, and the charge peaks have the same position and relative amplitude. Notably, the volt-off space charge profile at approximately $5 \mathrm{~s}$ after switch-off of the ac stress was just slightly smaller in amplitude than the all-phase averaged charge at $6 \mathrm{~h}$ of ac stress application. This finding indicates that the volt-off space charge comes from the all-phase averaged charge, which is virtually a stationary charge. The periodic charge vanished immediately after the switch-off of ac stress, whereas the stationary charge had a certain residence time and decreased gradually in the depolarization process.

As shown in the analysis above, the stationary charge presented a more remarkable variation than the periodic charge. The stationary charge has a close relationship with the application of ac aging stresses and requires particular attention. The essence of the all-phase averaged method is to clearly reveal the stationary charge, which is of great use for resolving space charge features under ac stress.

\subsection{RELATIONSHIP BETWEEN SPACE CHARGE AND THE DEGREE OF CROSSLINKING}

The tensile strength and degree of crosslinking increase at the first aging step and decrease afterwards. The increase in these quantities in the first step is revealed whatever the aging temperature. The variation in the degree of crosslinking with aging steps can be related to the competition between chain scission and crosslinking reactions, i.e., destruction and reforming of chemical bonds [43-46]. Under the combined effect of high electric field and thermal stress in the aging process, the microstructure of XLPE material in cable insulation is damaged due to the reduction of degree of crosslinking. At the same time, the free radicals generated from fractured chemical bonds tend to combine under the action of the temperature, which results in the reforming of molecular bonds and the enlargement of the degree of crosslinking. 
In the early stage of aging, the microstructure of the material is presumably damaged to a small degree, whereas a certain amount of dissociative end groups in molecular chains combine with each other under thermal stress. Therefore, the probability of chain crosslinking is stronger than that of chain decomposition in early aging, which accounts for the increase in the degree of crosslinking. In the middle and late aging stages, XLPE material suffers from the long-time action of electric field and thermal stress, which leads to severe damage of the microstructure. The probability of chain decomposition is stronger than that of chain crosslinking in the middle and late stages; hence, the degree of crosslinking decreases. Similar phenomena were reported recently, as revealed by infrared spectroscopy and thermo-kinetic analysis [47, 48].

A comparison of Figures 9-11 shows that the space charge quantity formed under ac stress has an opposite change tendency compared with the mechanical properties and the degree of crosslinking. Therefore, the variation of space charge with aging could be explained by change in material microstructure. In the early aging stage, chain crosslinking in XLPE material has a larger probability of occurrence than chain scission; thus, the defect is less concentrated in the cable insulation, and the space charge density captured by traps is correspondingly reduced [48]. In the middle and late aging stages, the structure of molecular chains is significantly damaged, and a large amount of chemical bonds are fractured. Therefore, the defect density increases, thereby increasing the space charge density.

\section{CONCLUSIONS}

The space charge features of cable insulation peelings under ac stress are studied using a space charge measurement system. Space charge under ac stress can be divided into two types: stationary charge and periodic charge. The space charge seems to change synchronously with ac phase angles, that is, space charge has the largest amplitude in angles of $90^{\circ}$ and $270^{\circ}$ in phase with voltage maxima. However, the space charge density in specific phase positions $\left(90^{\circ}\right.$ or $270^{\circ}$ for example) does not increase visibly. Thus, the all-phase averaged method is proposed to clearly present space charge build-up under ac stress, which can eliminate the periodic charge and reveal the stationary charge. Experimental results show that the stationary charge density increases as the thermo-electric aging time progresses.

The space charge characteristics of insulation peeling taken from cables aged in different ac conditions are compared by the all-phase averaged waveform. The trends for the stationary charge density exhibit a small reduction at the beginning of aging and an increase in the latter stages of aging, which has the opposite change tendency from the degree of crosslinking and the mechanical properties. The change of space charge with ac aging has a close relationship with defect concentration in cable insulation.

In the early aging stage, chain crosslinking in XLPE material has a larger probability of occurrence than chain decomposition. Thus, the defect concentration is reduced in the cable insulation, and the space charge density captured by traps is correspondingly reduced. In the middle and late aging stages, the structure of the molecular chains is damaged. Thus, the defect density increases, thereby increasing the space charge density.

\section{ACKNOWLEDGMENT}

This work is supported by the National Natural Science Foundation of China (Grant No. 51777117).

\section{REFERENCES}

[1] B. Du, W. Zhu, J. Li, et al, "Temperature-dependent surface charge behavior of polypropylene film under DC and pulse voltages", IEEE Trans. Dielect. Elect. Insul.,Vol. 24, No. 2, pp.774-783, 2017.

[2] M. Hao, Y. Zhou, G. Chen, G. Wilson and P.Jarman, "Space charge behavior in thick oil-impregnated pressboard under HVDC stresses", IEEE Trans. Dielectr. Electr. Insul.,Vol.22, No.1, pp. 72-80, 2013.

[3] J. P. Jones, J. P. Llewellyn, and T. J. Lewis, "The contribution of field-induced morphological change to the electrical aging and breakdown of polyethylene", IEEE Trans. Dielectr. Electr. Insul., Vol. 12, No. 5, pp. 951-966, 2005.

[4] L. A. Dissado, G. Mazzanti, and G. C. Montanari, "The role of trapped space charges in the electrical aging of insulating materials", IEEE Trans. Dielectr. Electr. Insul., Vol. 4, No. 5, pp. 496-506, 2002.

[5] Laurent, C., et al, "Charge dynamics and its energetic features in polymeric materials", IEEE Trans. Dielectr. Electr. Insul., Vol. 20, No. 2, pp. 357-381, 2013.

[6] K. S. Bromley, L. A. Dissado, and J. C. Fothergill, "Discharges, space charge, and the shape of electrical trees", IEEE International Conference on Conduction and Breakdown in Solid Dielectrics, Vasteras, Sweden, Sweden, pp.295-300, 1998.

[7] K. Wu, and L. A. Dissado, "Model for electrical tree initiation in epoxy resin", IEEE Trans. Dielectr. Electr. Insul., Vol. 12, No. 4, pp. 655-668, 2005.

[8] M, C. Mammeri, C. Laurent, and J. Salon, "Influence of space charge buildup on the transition to electrical treeing in PE under ac voltage", IEEE Trans. Dielectr. Electr. Insul., Vol. 2, No. 1, pp. 27-35, 1995.

[9] Y. Wei, H. Mu, J. Deng and G. Zhang, "Effect of space charge on breakdown characteristics of aged oil-paper insulation under DC voltage", IEEE Trans. Dielectr. Electr. Insul., Vol. 23, No. 5, pp. 3143-3150, 2016.

[10] G. Mazzanti, G. Chen, J. C. Fothergill, et al, "A protocol for space charge measurements in full-size HVDC extruded cables", IEEE Trans. Dielectr. Electr. Insul., Vol. 22, No. 1, pp. 21-34, 2015.

[11] G. C. Montanari, and D. K. Das-Gupta, "Polarization and space charge behavior of unaged and electrically aged crosslinked polyethylene", IEEE Trans. Dielectr. Electr. Insul., Vol. 7, No. 4, pp. 474-479, 2000.

[12] G. C. Montanari, A. Bulinski, and J. P. Crine, "A molecular model to evaluate the impact of aging on space charges in polymer dielectrics [comment and reply", IEEE Trans. Dielectr. Electr. Insul., Vol. 5, No. 3, pp. 461-462, 1998.

[13] Z. Xu, J. Zhao, and G. Chen, "An improved pulsed electroacoutic system for space charge measurement under AC conditions", IEEE International Conference on Solid Dielectrics, Potsdam, Germany, pp. $1-4,2011$.

[14] F. Baudoin, D.H. Mills, P.L. Lewin, S. Le Roy, G. Teyssedre and C. Laurent, "Modeling electroluminescence in insulating polymers under AC stress: effect of excitation waveform", J. Phys. D: Appl. Phys. Vol. 44, pp. 165402-01/11, 2011

[15] G. C. Montanari, F. Palmieri, G. Mazzanti, C. Laurent and G. Teyssedre, "AC charge injection investigated by means of space charge measurements: threshold and frequency dependence", IEEE International Conference on Properties and Applications of Dielectric Materials, Slavske, Ukraine, Ukraine, Vol. 3, pp. 895-899, 2003.

[16] X. Wang, N. Yoshimura, Y. Tanaka, K. Murata and T. Takada, "Space charge characteristics in cross-linking polyethylene under electrical stress from dc to power frequency," J. Phys. D: Appl. Phys., Vol. 31, No. 16, pp. 2057, 1998. 
[17] J.C. Fothergill, L.A. Dissado, J. Alison and A. See, "Advanced pulsed electro-acoustic system for space charge measurement", Seventh International Conference on Dielectric Materials, Measurements and Applications, Bath, UK, pp. 352-356, 2002.

[18] L. A. Dissado, G. Mazzanti, and G. C. Montanari, "Proposal of a space-charge life model for electrical polymeric insulation aged under AC voltage", Conference Record of the 1998 IEEE International Symposium on Electrical Insulation, VA, USA, Vol. 2, pp. 595-598, 2002.

[19] Y.F.F. Ho, H.G. Chen, A.E. Davies, S.G. Swingler, S.J. Sutton and R.N. Hampton, "Effect of semiconducting screen on the space charge dynamic in XLPE and polyolefin insulation under DC and $50 \mathrm{~Hz}$ AC electric stresses conditions", IEEE Trans. Dielectr. Electr. Insul., Vol. 10, No. 3, pp. 393-403, 2003.

[20] J. Zhao, Z. Xu, G. Chen, et al, "Space charge behavior in polyethylene under AC electric fields", IEEE Electrical Insulation and Dielectric Phenomena, Cancun, Mexico, pp. 105-108, 2011.

[21] Y. F. F. Ho, G. Chen, A. E. Davies, et al, "Measurement of space charge in XLPE insulation under $50 \mathrm{~Hz}$ ac electric stresses using the LIPP method", IEEE Trans. Dielectr. Electr. Insul., Vol. 9, No. 3, pp. 362-370, 2002.

[22] P. Notingher, A. Toureille, J. Santana,, et al, "Study of space charge accumulation in polyolefins submitted to ac stress", IEEE Trans. Dielectr. Electr. Insul., Vol. 8, No. 6, pp. 972-984, 2001.

[23] C. Thomas, G. Teyssedre, and C. Laurent, "A new method for signal averaging resorting to space charge measurements by the pulsed electro-acoustic method under AC stress", IEEE International Conference on Solid Dielectrics, Winchester, UK, pp. 486-489, 2007.

[24] C. Thomas, G. Teyssedre, and C. Laurent, "A New Method for Space Charge Measurements Under Periodic Stress of Arbitrary Waveform by the Pulsed Electro-Acoustic Method", IEEE Trans. Dielectr. Electr. Insul, Vol. 15, No. 2, pp. 554-559, 2008.

[25] S. Bamji, M. A. Dakka, and A. Bulinski, "Phase-resolved pulsed electro-acoustic technique to detect space charge in solid dielectrics subjected to AC voltage", IEEE Trans. Dielectr. Electr. Insul., Vol. 14, No. 1, pp. 77-82, 2007.

[26] D. He, W. Wang, J. Lu, et al, "Space charge characteristics of power cables under AC stress and temperature gradients", IEEE Trans. Dielectr. Electr. Insul., Vol. 23, No. 4, pp. 2404-2412, 2016.

[27] Y. L. Chong, G. Chen, H. Miyake, et al, "Space charge and charge trapping characteristics of cross-linked polyethylene subjected to ac electric stresses", J. Phys. D: Appl. Phys., Vol. 39, No. 8, pp. 1658-1666, 2006

[28] G. Chen, M. Fu, X. Z. Liu and L. S. Zhong, "ac aging and space-charge characteristics in low-density polyethylene polymeric insulation," J. Phys. D: Appl. Phys., Vol. 97, No. 8, pp. 401, 2005.

[29] C. Zhou, and G. Chen, "Space charge and AC electrical breakdown strength in polyethylene", IEEE Trans. Dielectr. Electr. Insul., Vol. 24, No. 1, pp. 559-566, 2017.

[30] A. Tzimas, S. M. Rowland and L. A. Dissado, "Effect of electrical and thermal stressing on charge traps in XLPE cable insulation", IEEE Trans. Dielectr. Electr. Insul., vol. 19, No. 6, pp. 2145-2154, 2012

[31] G. C. Montanari, "Bringing an insulation to failure: the role of space charge", IEEE Trans. Dielectr. Electr. Insul., Vol. 18, No. 2, pp. 339-364, 2011

[32] G. Mazzanti, G. C. Montanari, and L. A. Dissado, "A space-charge life model for ac electrical aging of polymers," IEEE Trans. Dielectr. Electr. Insul., Vol. 6, No. 6, pp. 864-875, 1999.

[33] A. Tzimas, M. Fu, L.A. Dissado et al., Space charge characterization of XLPE peelings with a cable prehistory: Before and after ac endurance tests", Proc. IEEE International Conference on Solid Dielectrics, pp. 474-477, 2007

[34] A. Tzimas, S. Rowland, L.A. Dissado et al., "Effect of long-time electrical and thermal stresses upon the endurance capability of cable insulation material", IEEE Trans. Dielectr. Electr. Insul.,, Vol. 16, No. 5, pp. 1436-1443, 2009.

[35] J.C. Fothergill, G.C. Montanari, G.C. Stevens et al., "Electrical, microstructural, physical and chemical characterization of HV XLPE cable peelings for an electrical aging diagnostic data base", IEEE Trans. Dielectr. Electr. Insul., Vol. 10, No. 3, pp. 514-527, 2003.
[36] C.M. Cooke, K.A. Wright, T. Maeno et al., "Pulsed electro-acoustic measurement of volume charge accumulation and decay in polyethylene", Proc. IEEE Conference on Electrical Insulation and\& Dielectric Phenomena, pp. 444-449, 1986.

[37] X. Wu, G. Chen, A.E. Davies, Y. Tanaka, S.J. Sutton and S.G. Swingler, "Space charge measurements in polyethylene under dc and ac operating conditions using the PEA technique", 8th Int. Conf. Dielectric Materials, Measurements and Applications, Edinburgh, UK, pp. 57-62, 2000.

[38] A. See, J.C. Fothergill, L.A. Dissado and J.M. Alison, "Measurement of space-charge distributions in solid insulators under rapidly varying voltage using the high-voltage, high speed pulsed electro-acoustic (PEA) apparatus", Meas. Sci. Technol., Vol. 12 pp. 1227-1234, 2001.

[39] C. Thomas, G. Teyssedre, C. Laurent C, "Space-charge dynamic in polyethylene: from dc to ac stress", J. Phys. D: Appl. Phys., Vol. 44, No. 1, p.015401, 2010.

[40] G.C. Montanari, G. Mazzanti, E. Boni and G. De Robertis, "Investigating ac space charge accumulation in polymers by PEA measurements", IEEE Conf. Electrical Insulation and Dielectric Phenomena (CEIDP), Victoria, Canada, pp. 113-116, 2000.

[41] A. Mao, "Investigation of the radial in homogeneity of the crosslinking degree in XLPE cable insulation", (In Chinese) Electric Wire \& Cable, No. 2, pp. 33-35, 2009.

[42] M. Li, "Comparison between the test methods for the measurement of the gel content in XLPE insulation compounds", (In Chinese) Electric Wire \& Cable, No. 4, pp. 33-35, 2006

[43] A. Oshima, S. Ikeda, E. Katoh, and Y. Tabata, "Chemical structure and physical properties of radiation-induced crosslinking of polytetrafluoroethylene", Radiation Phys. Chem., Vol. 62, No. 1, pp. 39-45, 2001.

[44] P. Chiniwalla, Y. Bai, E. Elce, R. Shick, W.C. McDougall, S.A.B. Allen, and P.A. Kohl, "Crosslinking and decomposition reactions of epoxide functionalized polynorbornene. Part I. FTIR and thermogravimetric analysis", J. Appl. Polymer Sci., Vol. 89, No. 2, pp. 568-577, 2003

[45] P. Vondráček, and A. N. Gent, "Slow decomposition of silicone rubber", J. Appl. Polymer Sci., Vol. 27, No. 11, pp. 4517-4522, 1982.

[46] W. Li, J. Li, X. Wang, et al, "Physicochemical origin of space charge dynamics for aged XLPE cable insulation", IEEE Trans. Dielectr. Electr. Insul., Vol. 21, No. 2, pp. 809-820, 2014.

[47] C. Chen, Z. Jia, W. Ye, Z. Guan and Y. Li, "Thermo-oxidative aging analysis of HTV silicone rubber used for outdoor insulation," IEEE Trans. Dielectr. Electr. Insul., Vol. 24, No. 3, pp. 1761-1772,2017.

[48] Y. Liu, H. Liu, L. Yu, Y. Li and L. Gao, "Effect of thermal stress on the space charge distribution of $160 \mathrm{kV}$ HVDC cable insulation material", IEEE Trans. Dielectr. Electr. Insul., Vol. 24, No. 3, pp. 1355-1364, 2017.

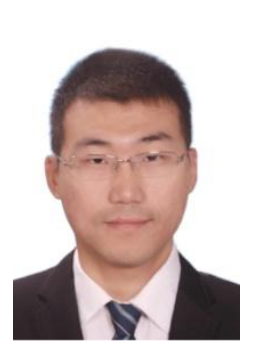

Dongxin He was born in Weifang City, China, in 1990. He received the B.S. degree in electrical engineering from Shandong University. He then enrolled in North China Electric Power University in Beijing and obtained the Ph.D. degree. In 2015, he travelled to the Laboratory of Plasma and Energy Conversion (LAPLACE) in Toulouse, France, as a visiting scholar.

Currently, he is a lecturer in Shandong University, Jinan, China. As a researcher, His current research interests include condition monitoring and fault diagnosis of power equipment, space charge in polymer materials especially in cable insulation under ac stress.

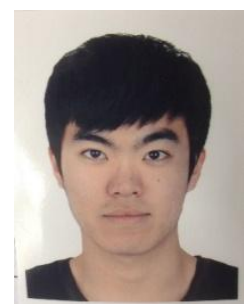

Xiaoran Wang was born Jinan, China. He received the B.S. degree from Shandong University, Jinan, China, in 2017.

$\mathrm{He}$ is currently pursuing the master's degree in electrical engineering in Shandong University,Shandong,China.His current research interests include space charge in polymer materials. 


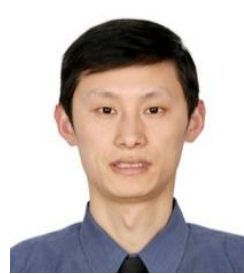

Hongshun Liu was born in Qingdao, China. He received the B.Sc.and Ph.D. degree in electrical engineering from Shandong University, Shandong, China, in 2004 and 2010, respectively.

Currently, he is a lecturer of Electrical Engineering at Shandong University, Shandong, China. His research interests include the modeling and simulation for power system electromagnetic transient processes, overvoltage and insulation coordination, condition monitoring and intelligent systems, high-voltage power electronics, etc.

Dr.Liu is a memer of the Institution of Engineering and Technology(IET) and the Chinese Society of Electrical Engineering(CSEE).

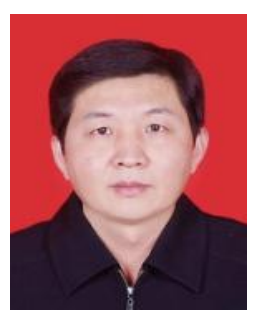

Qingquan Li was born in Laiwu city, Shandong Province, China, in 1969. He received the Ph.D. degrees in electrical engineering from Xi'an Jiaotong University, Xi'an, China, in 2003. Currently, he is a professor at Shandong University, Jinan, China. His research interests include the lightning protection and grounding technology, the high voltage insulation and measurement technology, and the detection and diagnosis techniques for electrical equipment.

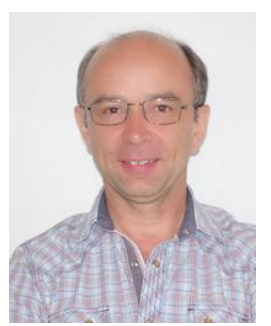

Gilbert Teyssedre was born in May 1966 in Rodez, France. He received his Engineer degree in materials physics and graduated in solid state physics in 1989 at the National Institute for Applied Science (INSA). Then he joined the Solid State Physics Lab in Toulouse and obtained the $\mathrm{Ph} . \mathrm{D}$. degree in 1993 for work on ferroelectric polymers. He entered the CNRS in 1995 and has been working since then at the Electrical Engineering Lab (now LAPLACE) in Toulouse. His research activities concern the development of luminescence techniques in insulating polymers with focus on chemical and physical structure, degradation phenomena, space charge and transport properties. He is currently Research Director at CNRS in a team working on the reliability of dielectrics in electrical equipment. 